\title{
Defining 'elderly' in clinical practice guidelines for pharmacotherapy
}

\author{
Received (first version): $\quad 3-J u l-2014$
}

Accepted: 15-Nov-2014

\begin{abstract}
${ }^{*}$
Objective: To identify how 'elderly' patients are defined and considered within Australian clinical guidelines for the use of pharmacotherapy.

Method: Guidelines pertaining to the use of pharmacotherapy, focusing on conditions described in National Health Priority Areas, were identified using databases (Medline, Google Scholar) and organisation websites (Department of Health and Ageing, National Heart Foundation, National Health and Medical Research Council). Guidelines were reviewed and qualitatively analysed to identify any references or definitions of 'elderly' persons.

Results: Among the 20 guidelines reviewed, 3 defined 'elderly' by chronological age (i.e., years since birth) while the remaining 17 guidelines did not define 'elderly' in any way. All 20 guidelines used the term 'elderly', whilst some guidelines provided age (chronological)-based dosage recommendations suggesting an ageist or generalist approach in their representation of 'elderly', for which rationale was seldom provided. Thematic analysis of the statements revealed five key themes regarding how 'elderly' was considered within the guidelines, broadly describing 'elderly' persons as being frail and with altered pharmacology. Some guidelines also highlighted the limited evidence base to direct clinical decision-making. A continuum of perceptions of ageing also emerged out of the identified themes.

Conclusion: Clinical practice guidelines currently do not adequately define 'elderly' persons and provide limited guidance on how to apply treatment recommendations to older persons. The representation of 'elderly' in guidelines needs to be less based on chronological age or generic definitions focusing more on establishing a direct link between an individual patient's characteristics and the pharmacology of their prescribed medication. Clinical guidelines that do not offer any practical descriptions of the features of ageing that are specifically related to the use of pharmacotherapy, or how to assess these in individual patients, render decision-making challenging.
\end{abstract}

Keywords: Aged; Drug Therapy; Practice Guidelines as Topic; Terminology as Topic

\footnotetext{
*'Shamsher SINGH. BPharm MPharm. School of Pharmacy, Graduate School of Health, University of Technology Sydney. Sydney, NSW (Australia). shamshersingh@student.uts.edu.au Beata BAJOREK. BPharm GradCertEdStud GDipClinPharm PhD. Associate Professor. School of Pharmacy, Graduate School of Health, University of Technology Sydney. Sydney, NSW (Australia). Beata.Bajorek@uts.edu.au
}

\section{INTRODUCTION}

Globally, the population is ageing and the World Health Organisation (WHO) predicts that, by 2050, the population aged 60 years or more will double, whilst those aged 80 years or more will number 400 million persons. ${ }^{1}$ This extension of the lifespan is looked upon as a triumph of medical advances, stemming from access to better treatments as well as a focus on preventive therapies; the use of pharmacotherapy is the key contributor to this. ${ }^{2}$ Overall, people are using more medication than ever before and, whilst the use of pharmacotherapy has helped people live longer, its use is more complicated and risk-prone in older persons. ${ }^{3}$ Herein lays the conundrum: pharmacotherapy has facilitated the ageing of the population, however, in the process, has created a population of persons that needs complex polypharmacy to manage their chronic health conditions ${ }^{3}$, but who also are at-risk of age-associated physiological, functional, and cognitive changes that increase the risk of adverse drug effects. ${ }^{4}$

Inappropriate prescribing is often observed in older persons, with reports of both over-treatment ${ }^{5}$ and under-treatment $^{6}$, rendering this population vulnerable to adverse clinical outcomes. Often, at the core of this inappropriate prescribing, is decision-making based on chronological age, which has sometimes been referred to as 'ageism' in the use of pharmacotherapy. ${ }^{7}$ Decision-making based on chronological age has been associated with the under-treatment of acute myocardial infarction ${ }^{6}$, congestive heart failure ${ }^{8}$, and atrial fibrillation. ${ }^{9}$ While there is no doubt that health care professionals possess the skills to make individualised treatment decisions, there are hot spots' in practice where decision-making is particularly challenging and which needs some support. The evidence-base specifically highlights the issues of potential age-biases in prescribing, and this is reinforced by emotive discussions taking place in various practice settings identifying the experiences of practitioners and patients alike. ${ }^{10,11}$ One classic example of this is in atrial fibrillation treatment; patients aged 80 years or more have been found to be five times less likely to receive warfarin compared to those aged less than 80 years. ${ }^{9}$

Ageing, an inevitable process, is commonly measured by chronological age and, as a convention, a person aged 65 years or more is often referred to as 'elderly'.12,13 However, the ageing process is not uniform across the population due to differences in genetics, lifestyle, and overall health. ${ }^{14}$ Thus, chronological age fails to address 
the heterogeneity observed among the 'elderly', particularly in regard to their pharmacotherapy needs where pharmacokinetic and pharmacodynamic factors necessitate individualisation of regimens. ${ }^{14}$ However, there are no concrete definitions of 'elderly' that appropriately characterise this patient population; in using the generic terms 'elderly' and 'older persons' (even within this manuscript) there may be variable interpretations of the type of patients that is being referred to, and this is problematic when decisionmaking specifically refers to these. These issues have never been more relevant to clinical practice, given the increasing emphasis on patient-centred care. ${ }^{15}$ Although, much attention has been paid to developing models and tools which help to individualise therapy (e.g., pharmacometrics ${ }^{16}$ and physiology-based pharmacokinetic (PBPK) modelling) ${ }^{17}$, seldom do they account for the diverse range of age-associated factors that influence decision-making in older persons. Moreover, these tools often include age as a determining parameter, with limited ability to tailor therapy to the needs of individual patients according to their unique attributes. For instance, one pharmacometric model defining the relationship between warfarin dose and the international normalised ratio has been based on genetic variations and chronological age only, without consideration of other key patient characteristics (e.g., comorbidities, polypharmacy, cognitive and functional impairments). ${ }^{18}$ Features of ageing must be appropriately considered within any strategy or tool (including clinical practice guidelines) focused on the individualisation of therapy.

Clinical practice guidelines are 'systematically developed statements to assist practitioner and patient decisions about appropriate health care for specific clinical circumstances'. ${ }^{19,20}$ A systematic review of clinicians' attitudes towards clinical guidelines has found that $70 \%$ of the clinicians agree that guidelines are an important source of information. However, $30 \%$ criticised these guidelines for their limited applicability to individual patients. $^{21}$ Thus, it is important to understand what limits the value of these guidelines in actual practice. The aim of this study was to explore how Australian clinical practice guidelines define an 'elderly' patient, to what extent treatment recommendations are made specifically using these terms, and how they consider age-related parameters in the use of pharmacotherapy.

\section{METHODS}

Figure 1 describes the search strategy, data extraction, and search results. A structured review of clinical practice guidelines relating to the use of pharmacotherapy in Australia was undertaken, specifically identifying within each guideline:

- Any specific definition of being 'elderly' (quantitative or qualitative definitions)

- Pharmacokinetic and pharmacodynamic considerations while defining 'elderly'
- Any age-specific consideration mentioned in the guidelines while making treatment recommendations

The focus was specifically on clinical conditions mentioned as National Health Priority Areas (NHPA) which include arthritis, asthma, cancer, cardiovascular health, diabetes, dementia, mental health, and obesity, accounting for $72.8 \%$ of the total disease and injury burden in Australia. ${ }^{22}$ In Australia, the development of clinical practice guidelines is primarily overseen by the National Health and Medical Research Council (NHMRC), and/or specific professional organisations and societies specialising in particular areas (e.g. National Heart Foundation, National Stroke Foundation). These clinical practice guidelines are principally directed toward those clinicians and practitioners who are involved in therapeutic decision-making, including prescribers and treatment reviewers.

Guidelines were sourced from an online repository (Clinical Practice Guidelines Portal- an initiative of the NHMRC) ${ }^{23}$ that was specifically developed to provide ready access to clinical guidelines via a single entry point. A search of the repository was undertaken to identify those guidelines addressing NHPAs, using key words relating to disease/condition names. Other key websites were additionally searched, including the Department of Health and Ageing, the National Heart Foundation of Australia, and NHMRC, as well as online databases, Google Scholar and Medline. Only current guidelines that were available in their entirety were selected for review, excluding those listed as rescinded. In total, 28 guidelines were initially identified, of which 8 were excluded from further review: 5 guidelines were listed as rescinded, and 3 guidelines were in fact only summaries of original guidelines. The remaining 20 guidelines were then reviewed in regard to their consideration of older persons in treatment recommendations.

To qualitatively analyse any descriptors of 'elderly', thematic analysis ${ }^{24}$ was applied to statements mentioning age related terms such as 'elderly' or "older". To ensure the reliability of the analysis (thematic coding and interpretation), the extracted statements were independently reviewed by both researchers. The themes were independently derived, before a joint discussion to ensure a consensus was reached. Once the core themes had been elicited, their relationship to each other was also explored.

\section{RESULTS}

Overall, 20 guidelines were reviewed (Table 1). Of these, 3 guidelines defined being 'elderly' using chronological age; two guidelines defined 'elderly' by chronological age of 65 years or more and one guideline used the chronological age of 75 years or more. The remaining 17 guidelines did not define 'elderly' by any specific measure. 
Databases searched

Medline

Google scholar
Websites searched

- $\quad$ Clinical Practice Guidelines portal

- Department of Health and Ageing

- Heart Foundation of Australia

- National Health and Medical Research Council (NHMRC)

17 guidelines sourced from Clinical Practice Guidelines portal

2 Guidelines sourced from the NHMRC website

1 guideline sourced from google scholar

Guidelines studied for any definition of 'elderly'

Statements with mention of terms 'elderly' or 'older' were collected

Total 20 guidelines were studied

$1 \mathrm{x}$ diabetes mellitus, neuropathic pain, respiratory health, obesity

$2 x$ for vascular disorders and mental health

$3 x$ musculoskeletal condition and cancer

$6 x$ cardiovascular condition

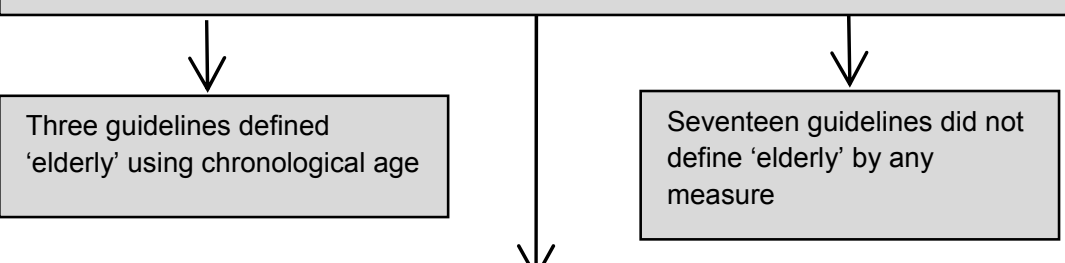

Key themes

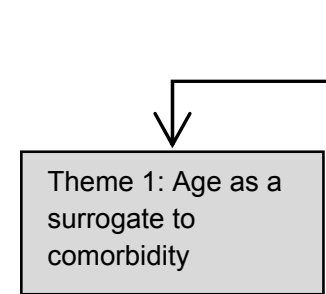

Theme 2: Altered drug pharmacology

Theme 5: Features

of frailty

Theme 3: Limited

evidence base

Theme 4: Old age, a contraindication to

treatment

Continuum of perceptions about ageing

\section{Awareness}

Population ageing, increased need to treat more 'elderly' patients

Acknowledgement
'Elderly' a
vulnerable
population, extra
caution

Isolation Treatment
exclusions, lack of
evidence base

Fear

Age-based dosage adjustments,

heterogeneity not addressed

Figure 1. Search strategy, data extraction, and search results

None of the 20 guidelines purposefully emphasised altered drug pharmacology in older persons to distinguish how the use of the pharmacotherapy might differ in the 'elderly'. However, the guidelines did include statements about specific recommendations, cautionary statements, referral procedures, diagnostic, and emergency care for 'elderly' patients. Five key themes emerged from the qualitative analysis of these statements, outlining how 'elderly' patients were variably 
Singh S, Bajorek B. Defining 'elderly' in clinical practice guidelines for pharmacotherapy. Pharmacy Practice 2014 Oct-Dec;12(4):489.

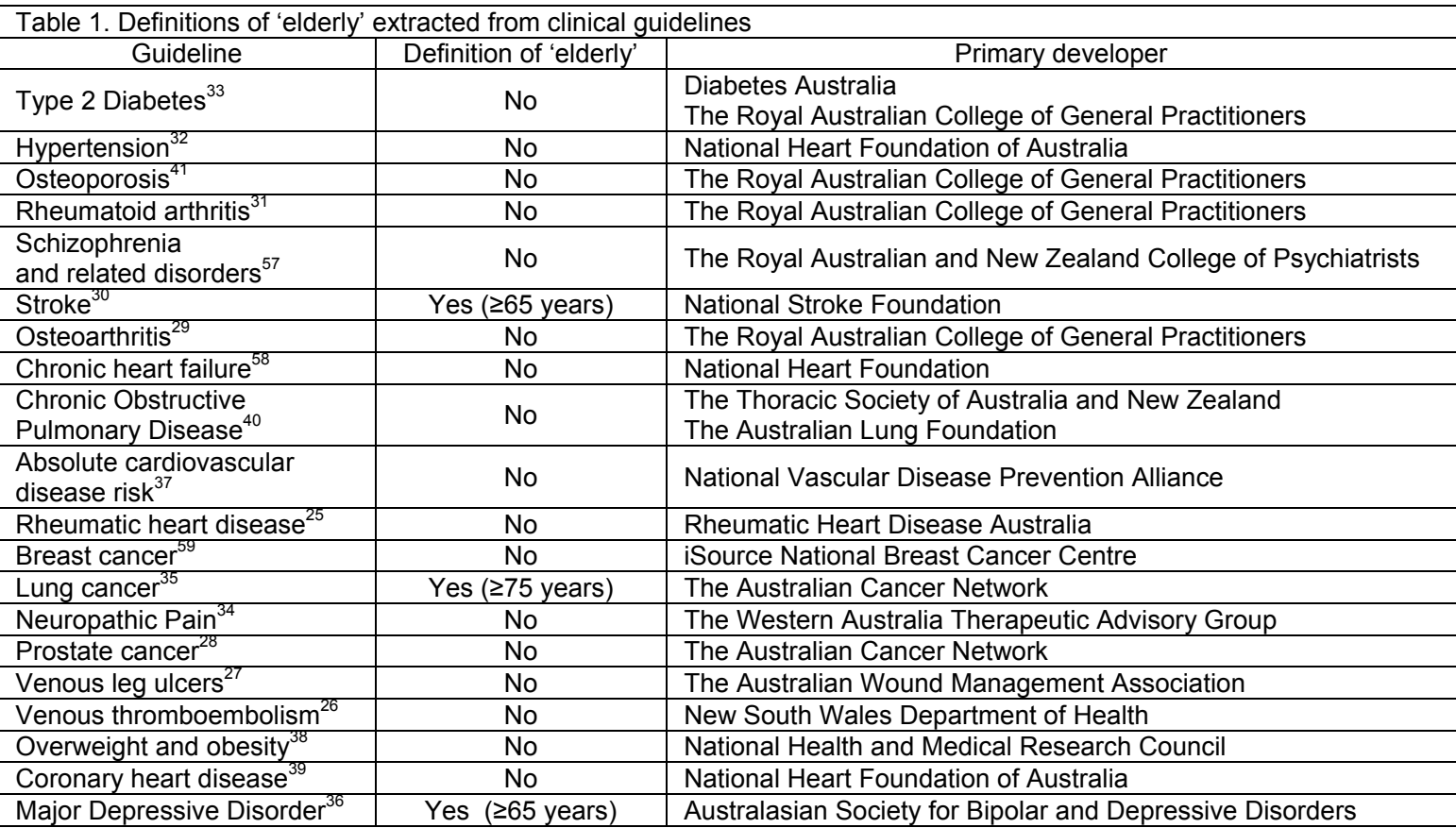

considered within practice guidelines. The elicited core themes were explored for their relationship to each other, and the continuum of perceptions about the different levels of understanding about 'ageing' and its application in decision-making was mapped: awareness, acknowledgement, isolation, fear, and evolution (Figure 1). The key themes were:

- Age as a surrogate to comorbidity (Awareness)

- Recognition of issues related to altered drug pharmacology in elderly patients (Acknowledgement, Isolation)

- Limited evidence base to define recommendations for older patients (Isolation)

- Old age is associated with restrictions to the use of pharmacotherapy (Isolation, Fear)

- Features of frailty may underpin treatment recommendations (Evolution)

\section{Age as a surrogate to comorbidity (Awareness)}

In four guidelines, the statements assumed that older persons had multiple co-morbidities and were at-risk of imminent death, almost treating the term 'elderly' as a surrogate for comorbidity and expected 'end of life'. Indeed, several guidelines acknowledged that the risk or prevalence of some diseases was higher in older persons, and therefore there was a need to treat more older persons, although none specifically described the considerations for using the therapies in this patient population.

"In most affluent populations, including much of Australia, ARF (Acute Rheumatic Fever) is now rare, and RHD (Rheumatic Heart Disease) occurs predominantly in the elderly". ${ }^{25}$

"As the majority of cancer patients are elderly, and as the incidence of VTE (Venous Thromboembolism) increases dramatically in patients aged greater than 55 years, most if not all cancer patients admitted to the hospital will fall into a high risk for subsequent VTE". ${ }^{26}$
"It is well established that VLUs (Venous Leg Ulcers) occur more often in older adults. ${ }^{27}$

"It is therefore evident that for the foreseeable future we will continue to need to care for a significant number of older men with metastatic disease". 28

\section{Recognition of issues related to altered drug pharmacology in elderly patients (Acknowledgement, Isolation)}

In less than half of the guidelines $(n=8)$, some statements stated the need to adjust drug doses in the elderly to reduce the risk of adverse drug outcomes. The underpinning link to the pharmacology of the therapy may be obvious to most clinicians, although none of the guidelines purposefully described the specific pharmacokinetic and pharmacodynamic considerations.

"GPs should apply caution when using traditional NSAIDs and COX-2 NSAIDs in view of the known side effects, especially in the elderly, and those on concomitant medications. Careful monitoring of blood pressure and renal function is indicated in older people and others at risk when using these agents". ${ }^{29}$

"GPs should commence opioids at low starting dose with slow titration dose, particularly in people at increased risk of adverse effects, such as the elderly, and closely monitor patients for adverse effects" ${ }^{29}$

"The known cardiotoxic risk of tricyclic antidepressants (especially in overdose) needs to be balanced by the analgesic benefits for more elderly patients with stroke". 30

"Addition of $\mathrm{Gl}$ protective drugs to conventional NSAIDs can significantly reduce complications such as the incidence of $\mathrm{Gl}$ 
bleeding and is recommended for RA patients over 65 years of age". ${ }^{31}$

"Commence at the lowest possible dose (ACE inhibitors and Angiotensin II receptor antagonists) in elderly patients and those taking diuretics". ${ }^{32}$

"Lowest doses (of Amlodipine and Felodipine) are recommended, particularly in the elderly". 22

"With sulphonylureas special care needs to be taken, especially in the elderly, not to precipitate hypoglycaemia". ${ }^{33}$

"Starting dose for pregablin is $75 \mathrm{mg}$ bd (25$50 \mathrm{mg}$ in the elderly and frail)". ${ }^{34}$

"Care should always be taken with opioid doses in the elderly and in the use of morphine in patients with renal failure". ${ }^{35}$

"More caution (with tricyclic antidepressants) is indicated in children and the elderly and at higher doses". ${ }^{36}$

\section{Limited evidence base to define recommendations for older patients (Isolation)}

The statements from only two guidelines implied or otherwise specifically stated that there was a limited evidence base for the use of pharmacotherapy in older persons, and therefore afforded no practical advice to assist clinical decision-making.

"However not all clinical situations in which their (blood pressure and lipid-lowering agents) use may be considered have been covered by clinical trials, e.g. in the elderly". ${ }^{37}$

"There is insufficient data to evaluate the safety and efficacy of weight loss medication $\ldots$ in older adults". ${ }^{38}$

\section{Old age is associated with restrictions to the} use of pharmacotherapy (Isolation, Fear)

A quarter of guidelines $(n=5)$ included statements that indicated that the use of pharmacotherapy should be restricted in older persons, and in some cases a specific chronological age was cited. The rationale for these restrictions was seldom provided, suggestive of potentially age-biased recommendations, some of which related to perceived safety considerations whilst other relating to treatment efficacy.

Recommendations based on perceived safety considerations:

"Prazosin not recommended in the elderly or patients with autonomic symptoms or cardiac failure". 33

"For patients with ACS (acute coronary syndromes) who are undergoing stenting, Prasugrel $10 \mathrm{mg} /$ day can be used as an alternative to Clopidogrel for 12 to 15 months. Avoid prescribing Prasugrel in patients with an increased risk of bleeding: for example, patients with history of smoke/TIA,low body weight $(<60 \mathrm{~kg})$, and advanced age (>75years)" ${ }^{39}$

Recommendations relating to efficacy:

"CEA (carotid endarterectomy) for asymptomatic carotid stenosis is more beneficial for men than women and for younger rather than older patients".

"Pneumococcal vaccination is known to be highly effective in preventing invasive bacteraemic pneumococcal pneumonia, but may be less effective in elderly or immunosuppressed patient". ${ }^{40}$

Unlike the preceding examples highlighting restrictions for the use of therapy in older persons, one statement, in contrast, limited the use of a therapy to 'older' patients only (in preference to younger persons).

"The use of thiazide diuretics as first line therapy (for hypertension) to be limited to older patients".

Such statements reflect an underestimation of remaining life expectancy in those aged 65 or more, and suggest that it may be appropriate to accept the risks of therapy more so in older persons.

\section{Features of frailty may underpin treatment recommendations (Evolution)}

Although none of the guidelines specifically discussed or described frailty, four guidelines included statements that suggested a link between frailty and ageing. Some of the recommendations mentioned attributes of old age (such as cognitive impairment, physical status) which may affect medication use/management in the elderly. Broadly speaking, the statements here address the concept of frailty and its application to clinical decisionmaking.

Recommendations associated with prescribing:

"Less (insulin dose) may be required in elderly, active, thin patients and more in the overweight and underactive". ${ }^{33}$

"Antihypertensive therapy should be initiated with caution in the very old or frail (patients with comorbid acute stroke condition)". ${ }^{32}$

"Calcium intake is often sub-optimal in the elderly (especially institutionalised patients)".

Generalised statements:

"Many older people already have limited mobility, and obesity is likely to aggravate the problem and increase the risk of further functional problem".

"The effect of excess weight on comorbidities such as Type 2 diabetes also reduce the ability of older people to participate in social and physical activities". 


\section{DISCUSSION}

A key finding of this study is that contemporary clinical guidelines either did not define 'elderly' by any useful means $(85 \%)$ and/or otherwise employed chronological age as a definition (15\%). While two guidelines defined those aged 65 or beyond as 'elderly', one guideline used 75 years as cut-off for its description of 'elderly'. This variability in setting a 'cut-off' chronological age while defining 'elderly' is another issue which impedes a uniform description of 'elderly'. Similar trends in variably defining 'elderly' have been observed in a range of diseasespecific clinical studies, for instance atrial fibrillation. $42-44$

Any underpinning characterisations of the 'elderly' appear to be very generic, not evidence-based, and potentially biased. Although most guidelines apparently consider the 'elderly' population as a vulnerable population when it comes to using pharmacotherapy, few guidelines are suggestive of the relationship between frailty and ageing, or the relationship between actual physiological changes and the pharmacological handling of a drug. More importantly, none of the guidelines identified that ageing is a heterogeneous process and therefore treatment use must be based on an individual assessment of relevant parameters underpinning the risk versus benefit of therapy.

Individualised pharmacotherapy begins with the realisation that vulnerability to a particular clinical condition, its course, and response to prescribed pharmacotherapy are dependent on multiple factors including ageing, gender, genetics, lifestyle, and social-cultural aspects. ${ }^{45}$ Based on these factors, differing significantly from person to person, patients can be stratified for treatment recommendations, supporting a patient-centre treatment approach. Any treatment recommendation presented by clinical guidelines that regard the 'elderly to be a homogenous group of people may limit the clinical benefits of therapy. ${ }^{46}$ For instance, one of the guidelines reviewed in this study limited the use of thiazide diuretics (associated with elevated risk of diabetes) as first line therapy to older people only. ${ }^{32}$

Few studies have systematically addressed the issue of chronological age-based descriptions of 'elderly' in clinical settings; however a few have argued the need to review definition. Orimo et al. ${ }^{13}$ considered that, given the improving health status and functional independence in older persons, changing cut-off age from 65 years to 75 years to define 'elderly'. Similarly, improvements in health, cognition, and functional abilities of those aged 70 or more were observed in a longitudinal study supporting the need to change the cut-off age for defining 'elderly'. ${ }^{47}$ However, some researchers have recommended other options for defining being 'old', for example, the use of biological age. ${ }^{48,49}$ In the context of clinical guidelines, it is important to base treatment recommendations on an individual assessment of those specific factors known to affect the use of a particular medication and avoid using generic age-based approaches. Other guidelines (not relevant to pharmacotherapy) also highlight the requirement of such an approach. ${ }^{50}$
Clinical practice guidelines are important tools, but are frequently criticised for their insensitivity towards the needs of, and/or their limited applicability to, the older patient population. ${ }^{51}$ The findings of this study support this, in that the reviewed guidelines failed to present a comprehensive or practical definition of 'elderly' either in qualitative or quantitative terms. Chronological age-based definitions of 'elderly', as presented in three guidelines, provide no insight about the actual health status and unique needs of a patient. Thus, such recommendations have limited ability to assist health professionals in decisionmaking. A patient's unique characteristics such as: altered drug handling, physical/functional and cognitive function, extent of comorbidity, polypharmacy, social situation, and quality of life, should be considered in clinical guidelines. Current guidelines only allude to these issues at a surfacelevel, without adequate definition and support, and a few continue to use relatively arbitrary definitions of ageing based on chronological age.

As the continuum of perception of 'ageing' ranges from 'awareness' to 'evolution', there is an increasing focus on to assist clinicians in prescribing for the 'elderly'. Tools such as STOPP and START criteria $^{52}$, BEERS criteria ${ }^{53}$, as well as pharmacistled review services ${ }^{54,55}$ can assist in rationalising therapy. The concept of frailty is also emerging as a more reliable predictor of the heterogeneity that exists in this potentially vulnerable population. ${ }^{49}$ The frailty index might be operationalised to determine the biological age of a patient ${ }^{48}$, providing a longitudinal measure of health status in an individual which can subsequently be applied to guide decision-making. ${ }^{14}$

The inclusion of only Australian guidelines is a potential limitation of this study. However, although Australian guidelines have often (historically) been derived from international ones, this is less common in contemporary practice. ${ }^{56}$ Whilst it is not expected that practice and guidelines differ substantially in Australia compared to comparable international settings, further research in this area is needed to confirm the full scope of the issues.

This study highlights the existing gaps in understanding of 'old' age and the 'elderly' underpinning some potential age-biases in medication prescribing, and highlighting the limited extent to which current clinical practice guidelines address this. Although clinicians' abilities are not in question here, it is apparent that clinical guidelines often do not provide enough guidance on how to translate recommendations to individual patients, particularly older persons. More attention needs to be paid to this within guidelines given that no other factor displays more inter-patient variability in its presentation than 'age'.

\section{CONCLUSIONS}

Clinical practice guidelines currently do not adequately define 'elderly' persons and provide limited guidance on how to apply treatment recommendations to older persons. The representation of 'elderly' in guidelines needs to be 
less based on chronological age or generic definitions focusing more on establishing a direct link between an individual patient's characteristics and the pharmacology of their prescribed medication. Clinical guidelines that do not offer any practical descriptions of the features of ageing that are specifically related to the use of pharmacotherapy, or how to assess these in individual patients, render decision-making challenging.

\section{CONFLICT OF INTEREST}

None to declare.

Funding: The preparation of this manuscript did not receive funding.

\section{DEFINIENDO 'ANCIANO' EN LAS GUÍAS DE PRÁCTICA CLÍNICA PARA FARMACOTERAPIA}

\section{RESUMEN}

Objetivo: Identificar como se define a los 'ancianos' y se les considera en las guías clínicas para uso de farmacoterapia.

Método: Usando bases de datos (Medline, Google Scholar) y páginas web de las organizaciones (Department of Health and Ageing, National Heart Foundation, National Health and Medical Research Council) se identificaron las guías relativas al uso de farmacoterapia centradas en problemas de salud. Se revisaron las guías y se analizaron cualitativamente para identificar referencias o definiciones de personas 'ancianas'.
Resultados: entre las 20 guías revisadas, 3 definían 'anciano' por la edad cronológica (i.e. años desde el nacimiento), mientras que las 17 guías restantes no definían 'anciano' de forma alguna. Las 20 guías usaban el término 'anciano', aunque algunas proporcionaban recomendaciones de dosificación basadas en la edad (cronológicas) sugiriendo un abordaje peyorativo o generalista en la representación del 'anciano', para lo que raras veces se proporcionaba una justificación. El análisis temático de las afirmaciones reveló cinco temas en relación a como el 'anciano' era considerado en las guías, describiendo en general al 'anciano' como personas frágiles con farmacología alterada. Algunas guías también remarcaban la evidencia limitada para la toma de decisiones clínicas. También emergía de los temas identificados una idea de continuo de la percepción de envejecimiento.

Conclusión: Las guías de práctica clínica no definen adecuadamente a las personas 'ancianas' y proporcionan una limitada orientación sobre cómo proveer recomendaciones de tratamiento a personas mayores. $\mathrm{La}$ representación de 'anciano' en las guías necesita estar menos basada en la edad cronológica o definición genérica, centrándose más en establecer un vínculo directo entre las características de un paciente individual y la farmacología de la medicación prescrita. Las guías clínicas que no ofrecen ninguna descripción práctica de los hechos del envejecimiento que se relacionan específicamente con la farmacoterapia, o como evaluar a esos pacientes individuales, provocan una toma de decisiones arriesgada,

Palabras clave: Anciano; Farmacoterapia; Guías de Práctica Clínica como Asunto; Terminología como Asunto

1. World Health Organisation. 10 facts on ageing and the life course. 2012 http://www.who.int/features/factfiles/ageing/ageing facts/en/index.html (accessed 02/02/2014).

2. Cherubini A, Corsonello A, Lattanzio F. Underprescription of Beneficial Medicines in Older People. Drugs Aging. 2012;29(6):463-475. doi: 10.2165/11631750-000000000-00000

3. Nyborg G, Straand J, Brekke M. Inappropriate prescribing for the elderly - a modern epidemic? Eur J Clin Pharmacol. 2012;68(7):1085-1094. doi: 10.1007/s00228-012-1223-8

4. Hubbard RE, O'Mahony MS, Woodhouse KW. Medication prescribing in frail older people. Eur J Clin Pharmacol. 2013;69(3):319-326. doi: 10.1007/s00228-012-1387-2

5. Hanlon JT, Wang X, Castle NG, Stone RA, Handler SM, Semla TP, Pugh MJ, Berlowitz DR, Dysken MW. Potential underuse, overuse, and inappropriate use of antidepressants in older veteran nursing home residents. J Am Geriatr Soc. 2011;59(8):1412-1420. doi: 10.1111/j.1532-5415.2011.03522.x

6. Tran CTT, Laupacis A, Mamdani MM, Tu JV. Effect of age on the use of evidence-based therapies for acute myocardia infarction. Am Heart J. 2004;148(5):834-841. doi: 10.1016/j.ahj.2003.11.028

7. Jacobson TA. Overcoming 'ageism' bias in the treatment of hypercholesterolaemia : a review of safety issues with statins in the elderly. Drug Saf. 2006;29(5):421-448.

8. Boyles PJ, Peterson GM, Bleasel MD, Vial JH. Undertreatment of congestive heart failure in an Australian setting. J Clin Pharm Ther. 2004;29(1):15-22. doi:10.1046/j.1365-2710.2003.00531.x

9. Krass I, Ogle SJ, Duguid MJ, Shenfield GM, Bajorek BV. The impact of age on antithrombotic use in elderly patients with non-valvular atrial fibrillation. Australas J Ageing. 2002;21(1):36-41. doi:10.1111/j.1741-6612.2002.tb00413.x

10. Fraenkel L, Rabidou N, Dhar R. Are rheumatologists' treatment decisions influenced by patients' age? Rheumatology (Oxford). 2006;45(12):1555-1557. doi:10.1093/rheumatology/kel144

11. Harries C, Forrest D, Harvey N, McClelland A, Bowling A. Which doctors are influenced by a patient's age? A multimethod study of angina treatment in general practice, cardiology and gerontology. Qual Saf Health Care. 2007;16(1):2327. doi:10.1136/qshc.2006.018036

12. World Health Organisation. Definition of an older or elderly person. WHO, Geneva, Switzerland. 2010. http://www.who.int/healthinfo/survey/ageingdefnolder/en/index.html (accessed 12/11/2013).

13. Orimo $\mathrm{H}$, Ito H, Suzuki T, Araki A, Hosoi T, Sawabe M. Reviewing the definition of "elderly". Geriatrics \& gerontology international. 2006;6(3):149-158. doi: 10.1111/j.1447-0594.2006.00341.x

14. Levine ME. Modeling the Rate of Senescence: Can Estimated Biological Age Predict Mortality More Accurately Than Chronological Age? J Gerontol A Biol Sci Med Sci. 2013;68(6):667-674. doi: 10.1093/gerona/gls233 
15. Ferguson LM, Ward H, Card S, Sheppard S, McMurtry J. Putting the 'patient' back into patient-centred care: An education perspective. Nurse Educ Pract. 2013;13(4):283-287. doi: 10.1016/j.nepr.2013.03.016

16. Lesko LJ, Schmidt S. Individualization of drug therapy: history, present state, and opportunities for the future. Clin Pharmacol Ther. 2012;92(4):458-466. doi: 10.1038/clpt.2012.113

17. Zhao P, Zhang L, Grillo JA, Liu Q, Bullock JM, Moon YJ, Song P, Brar SS, Madabushi R, Wu TC, Booth BP, Rahman NA, Reynolds KS, Gil Berglund E, Lesko LJ, Huang SM. Applications of Physiologically Based Pharmacokinetic (PBPK) Modeling and Simulation During Regulatory Review. Clin Pharmacol Ther. 2011;89(2):259-67. doi: 10.1038/clpt.2010.298

18. Hamberg AK, Wadelius M, Lindh JD, Dahl ML, Padrini R, Deloukas P, Rane A, Jonsson EN. A Pharmacometric Model Describing the Relationship Between Warfarin Dose and INR Response With Respect to Variations in CYP2C9, VKORC1, and Age. Clin Pharmacol Ther. 2010;87(6):727-734. doi: 10.1038/clpt.2010.37

19. Field MJ, Lohr KN. Clinical Practice Guidelines: directions for a new program. Washington, DC: Institute of Medicine, National Academy Press; 1990.

20. Tricoci P, Allen JM, Kramer JM, Califf RM, Smith SC. Scientific evidence underlying the ACC/AHA clinical practice guidelines. JAMA. 2009;301(8):831-841. doi: 10.1001/jama.2009.205

21. Farquhar CM, Kofa EW, Slutsky JR. Clinicians' attitudes to clinical practice guidelines: a systematic review. Med J Aust. 2002;177(9):502-506.

22. AlHW, Begg S, Vos T, Barker B, Stevenson C, Stanley L, Lapez A. The burden of disease and injury in Australia 2003. 2007. http://www.aihw.gov.au/publication-detail/?id=6442467990 (accessed 8/10/2014).

23. Clinical Practice Guidelines Portal. https://www.clinicalguidelines.gov.au/ (accessed 23/10/2014).

24. Joffe H, Yardley L. Content and thematic analysis. In: Research methods for clinical and health psychology. London; SAGE; 2004. ISBN: 9780761971917

25. RHD Australia (ARF/RHD writing group) National Heart Foundation of Australia and the Cardiac Society of Australia and New Zealand. Australian guideline for prevention, diagnosis and mangement of acute rheumatic fever and rheumatic heart disease. 2012. http://www.rhdaustralia.org.au/sites/default/files/guideline 0.pdf (accessed 14/03/2014).

26. National Health and Medical Research Council. Clinical practice guideline for the prevention of venous thromboembolism (deep vein thrombosis and pulmonary embolism) in patients admitted to Australian hospitals. Melbourne: National Health and Medical Research Council. 2009.

http://www.nhmrc.gov.au/ files nhmrc/file/nics/programs/vtp/guideline prevention venous thromboembolism.pdf (accessed 18/03/2014).

27. Australian and New Zealand Clinical practice Guideline for Prevention and Management of Venous Leg Ulcers. http://www.awma.com.au/publications/2011 awma vlug.pdf (accessed 22/03/2014).

28. Australian Cancer Network Management of Metastatic Prostate Cancer Working Party. Clinical Practice Guidelines for the Management of Locally Advanced and Metastatic Prostate Cancer. Cancer Council Australia and Australian Cancer Network, Sydney. 2010.

http://www.cancer.org.au/content/pdf/HealthProfessionals/ClinicalGuidelines/FINAL Advanced Prostate Cancer Guide lines.pdf (accessed 05/03/2014).

29. Guideline for the non-surgical management of hip and knee osteoarthritis. 2009. http://www.racgp.org.au/download/documents/Guidelines/Musculoskeletal/racgp oa guideline.pdf (accessed 03/03/2014).

30. National Stroke Foundation. Clinical Guidelines for Stroke Management. Melbourne Australia. 2010. http://strokefoundation.com.au/site/media/clinical guidelines stroke managment 2010 interactive.pdf (accessed 10/03/2014)

31. Clinical guideline for the diagnosis and management of early rheumatoid arthritis. 2009. http://www.racgp.org.au/download/documents/Guidelines/Musculoskeletal/racgp ra guideline.pdf (accessed 16/02/2014)

32. National Heart Foundation of Australia (National Blood Pressure and Vascular Disease Advisory Committee). Guide to management of hypertension 2008. Updated December 2010. 2008. http://www.heartfoundation.org.au/SiteCollectionDocuments/HypertensionGuidelines2008to2010Update.pdf (accessed 28/02/2014)

33. Diabetes Management in General Practice 2011/12. http://www.racgp.org.au/download/documents/Guidelines/Diabetes/201107diabetesmanagementingeneralpractice.pdf (accessed 13/03/2014).

34. Western Australian Therapeutic Advisory Group. Guidelines for the Treatment of Neuropathic Pain. 2013. http://www.watag.org.au/watag/docs/130717 Advisory\%20Note Neuropathic\%20Pain\%20Guidelines\%20ver2.pdf (accessed 13/03/2014).

35. The Australian Cancer Network. Clinical Practice Guidelines for the Prevention, Diagnosis and Management of Lung Cancer. 2004. http://www.nhmrc.gov.au/ files nhmrc/publications/attachments/cp97.pdf (accessed 13/03/2014).

36. Dodd S, Malhi GS, Tiller J, Schweitzer I, Hickie I, Khoo JP, Bassett DL, Lyndon B, Mitchell PB, Parker G, Fitzgerald PB, Udina M, Singh A, Moylan S, Giorlando F, Doughty C, Davey CG, Theodoros M, Berk M. A Consensus Statement for Safety Monitoring Guidelines of Treatments for Major Depressive Disorder. Aust N Z J Psychiatry. 2011;45(9):712-725. doi: 10.3109/00048674.2011.595686

37. National Vascular Disease Prevention Alliance. Guidelines for the management of absolute cardiovascular disease risk 2012. http://strokefoundation.com.au/site/media/AbsoluteCVD GL webready.pdf (accessed 13/03/2014).

38. National Health and Medical Research Council. Clinical practice guidelines for the management of overweight and obesity in adults, adolescents and children in Australia. 2013. http://www.nhmrc.gov.au/ files nhmrc/publications/attachments/n57 obesity guidelines 131003.pdf (accessed 15/03/2014). 
39. National Heart Foundation of Australia and the Cardiac Society of Australia and New Zealand. Reducing risk in heart disease: an expert guide to clinical practice for secondary prevention of coronary heart disease., Melbourne: National Heart Foundation of Australia. 2012. http://www.heartfoundation.org.au/SiteCollectionDocuments/Reducing-risk-inheart-disease.pdf (accessed 13/03/2014).

40. Frith PA. The COPDX Plan: Australian and New Zealand guidelines for the management of chronic obstructive pulmonary disease 2003. Med J Aust. 2003;178(Suppl):S7-S39.

41. Clinical guieline for the prevention and treatment of osteoporosis in postmenopausal women and older men. 2010. http://www.racgp.org.au/download/documents/Guidelines/Musculoskeletal/racgp osteo guideline.pdf (accessed 15/03/2014)

42. Mant J, Hobbs FDR, Fletcher K, Roalfe A, Fitzmaurice D, Lip GYH, Murray E. Warfarin versus aspirin for stroke prevention in an elderly community population with atrial fibrillation (the Birmingham Atrial Fibrillation Treatment of the Aged Study, BAFTA): a randomised controlled trial. Lancet.370(9586):493-503. doi: 10.1016/S0140-6736(07)61233-1

43. Carlsson J, Tebbe U, Rox J, Harmjanz D, Haerten K, Neuhaus K-L, Seidel F, Niederer W, Miketic S. Cardioversion of atrial fibrillation in the elderly. Am J Cardiol. 1996;78(12):1380-1384. doi: 10.1016/S0002-9149(96)00647-9

44. Guiot A, Jongnarangsin K, Chugh A, Suwanagool A, Latchamsetty R, Myles JD, Jiang Q, Crawford T, Good E, Pelosi F Jr, Bogun F, Morady F, Oral H. Anticoagulant Therapy and Risk of Cerebrovascular Events After Catheter Ablation of Atrial Fibrillation in the Elderly. J Cardiovasc Electrophysiol. 2012;23(1):36-43. doi: 10.1111/j.1540-8167.2011.02141.x

45. Kraft K, Hoffmann W. Challenge of evidence in individualized medicine. Per Med. 2012;9(1):65-71.

46. Cho S, Lau S, Tandon V, Kumi K, Pfuma E, Abernethy DR. Geriatric drug evaluation: where are we now and where should we be in the future? Arch Intern Med. 2011;171(10):937-940. doi:10.1001/archinternmed.2011.152

47. Jacobs JM, Maaravi Y, Cohen A, Bursztyn M, Ein-Mor E, Stessman J. Changing Profile of Health and Function from Age 70 to 85 Years. Gerontology. 2012;58(4):313-321. doi: 10.1159/000335238

48. Goggins WB, Woo J, Sham A, Ho SC. Frailty Index as a Measure of Biological Age in a Chinese Population. J Gerontol A Biol Sci Med Sci. 2005;60(8):1046-1051. doi:10.1093/gerona/60.8.1046.

49. Mitnitski AB, Graham JE, Mogilner AJ, Rockwood K. Frailty, fitness and late-life mortality in relation to chronological and biological age. BMC Geriatr. 2002;2:1.

50. Guidelines for the ethical management of people with advanced chronic or terminal conditions in the final months of life. 2011. https://www.nhmrc.gov.au/guidelines/publications/rec31 (accessed 28/05/2014).

51. Carlsen B, Glenton C, Pope C. Thou shalt versus thou shalt not: a meta-synthesis of GPs' attitudes to clinical practice guidelines. Br J Gen Pract. 2007;57(545):971-978. doi: 10.3399/096016407782604820

52. O'Mahony D, Gallagher P, Ryan C, Byrne S, Hamilton H, Barry P, O'Connor M, Kennedy J. STOPP \& START criteria: A new approach to detecting potentially inappropriate prescribing in old age. Eur Geriatr Med. 2010;1(1):45-51. doi: 10.1016/j.eurger.2010.01.007.

53. American Geriatrics Society 2012 Beers Criteria Update Expert Panel. American Geriatrics Society updated Beers Criteria for potentially inappropriate medication use in older adults. J Am Geriatr Soc. 2012;60(4):616-631. doi: 10.1111/j.1532-5415.2012.03923.x

54. Vinks THAM, Egberts TCG, De Lange TM, De Koning FHP. Pharmacist-based medication review reduces potential drug-related problems in the elderly: the SMOG controlled trial. Drugs Aging. 2009;26(2):123-133. doi: 10.2165/0002512-200926020-00004

55. Castelino RL, Bajorek BV, Chen TF. Are interventions recommended by pharmacists during Home Medicines Review evidence-based? J Eval Clin Pract. 2011;17(1):104-110. doi: 10.1111/j.1365-2753.2010.01375.x

56. National Health and Medical Research Council. 2014 Annual Report on Australian Clinical Practice Guidelines. 2014. https://www.nhmrc.gov.au/ files nhmrc/publications/attachments/nh165 2014 nhmrc clinical guidelines annual repor t 140805.pdf (accessed 10/10/2014).

57. Royal Australian and New Zealand College of Psychiatrists clinical practice guidelines for the treatment of schizophrenia and related disorders. Aust N Z J Psychiatry. 2005;39(1-2):1-30. doi: 10.1080/j.1440-1614.2005.01516.x

58. National Heart Foundation of Australia and the Cardiac Society of Australia and New Zealand (Chronic Heart Failure Guidelines Expet Writing Panel). Guidelines for the prevention , detection and mangement of chronic heart failure in Australia. In: Updated October 2011.

http://www.heartfoundation.org.au/SiteCollectionDocuments/Chronic Heart Failure Guidelines 2011.pdf (accessed 23/03/2014)

59. iSource National Breast Cancer Centre. Clinical practice guidelines for the management of early breast cancer: Second edition. http://www.nhmrc.gov.au/ files nhmrc/publications/attachments/cp74.pdf (accessed 13/03/2014). 